\title{
REPORT ON LEPROSY IN BARBADOS
}

\author{
E. Muir
}

At the request of the British Empire Leprosy Relief Asso. ciation, I visited Barbados, arriving on the 13 th January, i942. A previous visit was made by my predecessor, Dr. Robert Cochrane, in September, 1934. As arranged by the Chief Medical Officer, I gave a series of talks and demonstrations on leprosy to between 17 and 19 doctors, and addressed a public meeting at which His Excellency the Governor presided and about 700 were present.

All anti-leprosv measures in Barbados centre round the "Lazaretto," which is situated some three miles north of the centre of Bridgetown, the capital. I visited this institution in company with the Chief. Medical Officer, the Visiting Physician and the Superintendent.

\section{LAZARETTO.}

This institution stands on a site of $32 \frac{1}{2}$ acres. The buildings are of permanent stone and cement structure, and I found everything very clean and tidy. The patients are lodged in wards, some of which are sub-divided with wood and canvas into separate dormitories. Some of the wards have been closed, as the number of patients is now far less than formerly. There are separate male and female quarters, each of which is surrounded bv a high wall surmounted with barbed wire. Patients are not allowed to go outside, but friends are allowed 
to visit them three days a week, precautions being taken to avoid infection.

The Staff consists of a part-time visiting physician, who visits the institution daily, a superintendent, an assistant steward, 16 attendants, and a matron.

Patients. There are at present 28 male and 28 female patients. The following table shows the number of patients, admissions, discharges and deaths for the last 17 years:

ADMISSIONS.

\begin{tabular}{|c|c|c|c|c|c|c|c|c|}
\hline$\underset{\text { d्र }}{\dot{d}}$ & 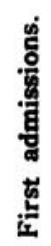 & 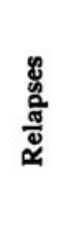 & 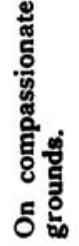 & $\underset{H}{\stackrel{\leftrightarrow}{\leftrightarrow}}$ & 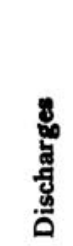 & 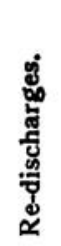 & 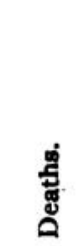 & 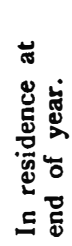 \\
\hline $19^{2} 4$ & 0 & 0 & 0 & 0 & 0 & 0 & 0 & 173 \\
\hline 1925 & 7 & 0 & 0 & 7 & 3 & 0 & 6 & 171 \\
\hline 1926 & 8 & 0 & 0 & 8 & 14 & 0 & 7 & $5^{8}$ \\
\hline 1927 & 9 & 1 & 0 & 10 & 17 & 0 & 10 & 141 \\
\hline 1928 & 5 & 2 & 0 & 7. & 9 & 0 & 9 & 130 \\
\hline 1929 & 6 & 0 & 2 & 8 & 13 & 0 & 10 & 115 \\
\hline 1930 & 6 & 2 & 3 & II & 8 & 0 & 6 & 112 \\
\hline 1931 & 6 & 0 & 2 & 8 & 9 & 0 & 9 & 102 \\
\hline 1932 & 5 & 0 & I & 6 & 7 & 0 & 12 & 89 \\
\hline 1933 & 8 & 0 & 2 & 10 & 5 & 0 & 8 & 86 \\
\hline 1934 & I & 2 & $\mathbf{I}$ & 4 & 5 & 0 & 10 & 75 \\
\hline 1935 & 5 & 2 & 5 & 12 & 0 & 3 & 5 & 79 \\
\hline 1936 & 2 & 8 & 1 & II & 3 & o & 13 & 74 \\
\hline 1937 & 2 & 2 & 0 & 4 & 2 & 0 & 7 & 69 \\
\hline I938 & 6 & 5 & 0 & 11 & 2 & 0 & 8 & 70 \\
\hline 1939 & 1 & o & 0 & 1 & 2 & 0 & 11 & 58 \\
\hline & 5 & 2 & 0 & & 1 & 0 & 7 & 57 \\
\hline \multirow[t]{2}{*}{1841} & 4 & I & 5 & 10 & 0 & 3 & 7 & 56 \\
\hline & 86 & 27 & 22 & 135 & 100 & 6 & 145 & \\
\hline
\end{tabular}

It will be noticed that the number of patients is now only a third of that in the end of 1924. Those admitted "on compassionate grounds" are ex-lepers who have contracted trophic lesions or other ailments without any return of active leprosy. They are taken in for a short period and fed and nursed until they are fit to go out again.

It is noticeable that while the number of deaths durin? the first seven years of this period is 0.77 times that of discharges, during the last to years the number of deaths is about 3.26 times that of discharges. The main reason for this appears to be that in the former vears there were many hopeful cases which recovered, but in the latter years a residue of irrecoverable cases has gradually accumulated, while new admissions of hopeful cases have been less and less. 
This fact has an important braring on the mental atmosphere of the institution. (Once hope of recovery has been lost there is a tendency for the mental outlook to become circumscribed and narrow, and this is the more so when patients become crippled and increasingly incapable of taking part in active work. It is easily understood that the minority of less advanced cases, who under favourable circumstances might hope to recover, are adversely influenced by this depressing mental atmosphere.

Also the smallness of the number of active and hopeful cases make it difficult to organise communal or social activities for their benefit. This is a matter of extreme importance, as one of the most important ${ }^{\circ}$ requirements for recovery is cheerfulness and mental and physical activity.

The general atmosphere of the I.azaretto is further indicated by the frequent complaints which the patients make about food, conduct of the staff and other matters. Trivial occurrences are exaggerated into serious matters, and life is marle hitter bv a feeling of discontent.

The remedy for this kind of conduct is not repeated concessions, but provision for more opportunities of activity and self-expression.

As regards the hopeful cases, it would be well if provision could he made for them to be transferred to some larger leprosarium such as that in Trinidad or British Guiana, where there is whole-time expert medical supervision and where the prevalent atmosphere is one of hopofulness and activitv. There are manv difficulties in the way of such a scheme and special lerislation would first he necessary.

An alternative method would he to segregate the hopeful matients in a separate part of the institution and make special arrangements for employment, exercise and other forms of treatment along modern lines.

\section{Present State of T.eprosy in the Colony.}

While the marked diminution of admissions to the I.azaretto shewn in the above table seems to indicate that leprosy is diminishing in the Colony, this indication must be taken with reserve for the following reasons:

(a) The I azaretto, as we have just indicated, has become less and less attractive as the prevailing type of inmate hecame increasingly hopeless and disabled.

(b) Only those lepers who are convicted of plying certain 
trades, or using hotels or other public buildings, or are found begging in the streets, are liable to compulsory intermment. Ihus all who have a competence of their own or have triends who are willing to support them can reman at home, and they are not likely to seek voluntary admission to the Lazaretto. Indeed, 1 am informed by the visiting physician inat voluntary admissions are very rare indeed.

(c) Leprosy is a disease which is not difficult to hide. This is especially so during the first few years of the mor severe and dangerous type. Exammation of the painents admitted durming the previous three years showed mme. remales and six males. Of these fifteen, seven have been admitted for less than one year, and six for less than two years. With one exception all were infectious cases, and twelve were highly infectious. Thus twelve must have had opportunities of spreading leprosy for three or more years before intermment.

We have to contess, therefore, that we have at present no reliable data for calculating the amount of leprosy in the colony or for estmuating whether or to what extent it is dimmishing under the present methods used for its control. I have aiscussed this matter with the doctors who attended the course of demonstrations reterred to above, and it seems to be their unanimous opinion that there is a great deal of leprosy at large in Barbados and that the present control system is quice inadequate.

\section{Distribution OF LEPROSY IN BARBADOS.}

Uur only figures for determining which parts of the Island are inost affected are the records of admission to the Lazaretto. The following table shows the number or lepers admitted from each parish during the last 40 years.

\begin{tabular}{|c|c|c|c|}
\hline Parish. & $\begin{array}{l}\text { Lepers } \\
\text { admitted. }\end{array}$ & $\begin{array}{l}\text { Total population } \\
\text { of parish in } \\
\text { thousands. }\end{array}$ & $\begin{array}{l}\text { Lepers } \\
\text { per thousand } \\
\text { admitted. }\end{array}$ \\
\hline St. Michael & 245 & 79 & 3.00 \\
\hline Christ Church & 57 & 27 & 2.11 \\
\hline St. Philip & $\ldots$ & 14 & 3.43 \\
\hline St. George & 19 & 14 & 1. 36 \\
\hline St. John & $\ldots$ & 9 & 2.22 \\
\hline St. James & $\ldots$ & II & 2.00 \\
\hline St. Thomas & $\ldots$ & 9 & 0.66 \\
\hline St. Peter & $\ldots$ & 9 & 2.00 \\
\hline St. Lucy & 13 & 7 & 1.86 \\
\hline St. Joseph & $\ldots$ & 7 & 1.00 \\
\hline St. Andrew & $\ldots$ & 7 & 0.29 \\
\hline
\end{tabular}

While more than half the lepers came from St. Michael's 
parish including Bridgetown, it is to be noted that St. Philip furnished a larger number per thousand of the population.

When the admission figures are looked into more particularly it is found that there were 28 admissions from Black Rock, 18 from Nelson Street and Golden Square, 14 from Cheapside and I.akes Folly, 14 from Wharf, I 3 from Beckles Road, 9 each from Carrington's Village and Chapman's Lane.

It is found, moreover, that 378 of the total 457 cases come from 79 foci and that 209 come from 28 foci.

A few points of importance can be deducted from the above figures :

(I) The fact that leprosy tends to concentrate in towns as shown by the large number in St. Michael's parish.

(2) That in spite of this leprosy is a disease of villages and small communities as shown by the high incidence per thousand in a remote rural area like St. Philip.

(3) Although leprosy is not a hereditary disease it tends to concentrate in small social foci such as a family or group of neighbouring families.

From this we may deduce the importance of thorough and repeated examination of contacts of all known cases; and, as leprosy is a disease which may take years to develop, these examinations should, at least in some cases, be repeated for a number of years.

Suggestions For. THE Control OF LeProsy IN Barbados.

I would suggest the use of the method which was developed in India and which in various modifications has been adopted in many parts of the tropics and sub-tropics. This is a triple system including education, treatment and survey.

\section{(I) Education.}

One of the difficulties in the way of control is the ignorance of the public regarding leprosy, and various misconceptions that they have about the disease. Once they come to realise its true nature, that in most cases it can be got rid of if treated early, then they are likely to come forward for early treatment and not as at present conceal it as long as they are able. Concealment has two disastrous effects: the disease passes on beyond the early remediable stage without effectual treatment; and others are infected by contact since the patient takes no steps to isolate himself.

(2) Treatment.

The majority of early cases are generally found to be 
suitable for out-paticnt or domiciliary treatment before they have reached the infectivus stage. It is the dread of the Lazaretto and the stigma of bemg known to the public as a leper that drives to conccalment.

(3) Survey.

From what is written above it seems obvious that all contacts with known cases should be exammed thoroughly and repeatedly, and at the same time the nature of leprosy should be particularly explanned to them so that they may understand the dangers and may come forward at once for medical examination as soon as any suspicious signs begin to appear. It is important also that all physicians, health officers, sanitary inspectors, and health nurses should be familiar with the early signs of leprosy.

In order to carry out the above programme, the following would be necessary :

(1) Provision of a doctor who, after making an intensive study of leprosy, would be responsible for anti-leprosy activity in the Colony and act as leprosy spccialist. The duties involved would entail a large amount of work to begin with, but after this period was over only part-time service would be required. I would suggest that the intensive study of leprosy might be made at Chacachacare (Trinidad) and Mahaica (British Guiana) and should extend over a period of three or four months.

(2) Amendment of the Lepers Act so that examination of contacts would become compulsory. If the scheme werc successfully worked, however, it should generally not be necessary to invoke the law for this purpose.

(3) Provision of suitable quarters for hopeful cases who, on account of infectiousness or need of careful treatment, require residence in an institution. These quarters would either be at the present Lazaretto or clsewhere, but in any case would be entirely shut off from the quarters of the hopeless incurable cases. The place would be made as attractive as possible, and would provide for occupational therapy and other treatment along modern lines, so that patıents would seek voluntary admission with a vicw to recovery.

(3a) A much more satisfactory alternative to providing quarters for hopeful cases in Barbados itself would be an arrangement for such cases to be sent to a large leprosarium such as that in Trinidad or British Guiana, where they could have the advantage of modern treatment under 
favourable circumslances; expenses would be met by the Government of Barbados or by the West Indian Development and Social Welfare Fund. To arrange this, however, three difficulties would have to be overcome:

(i) The law forbidding the entrance of non-domiciled lepers to these countries would have to be amended.

(ii) Patients might object to being exiled so far from home and relatives.

(iii) It might be difficult to arrange for suitable transport.

(4) Facilities in one or more clinics for the treatment of carly non-infectious cases. Such clinics could be held once a week at the Hospital, almshouses or other suitable places and would be under the charge of the lesprosy Specialist. In Trinidarl such clinics are proving very popular and some patients have recovered within a few months.

(5) I would suggest the formation of the Barbados Branch of the British Empire I eprosy Relief Association along the lines of the Branch in British Guiana. This might suitably be an expansion of the existing After-Care Committee which looks after the interests of discharged patients. Its functions would be :

(a) To arrange for lectures and other means of informing the public about the nature of leprosy.

(b) To take an interest in and afford help to, the patients in the Lazaretto by arranging entertainments and providing literature and comforts.

(c) To help as far as possible discharged patients and look after their welfare.

Objection is often made to taking active measures for the control of leprosy on the ground that there are other much more serious problems such as tuberculosis and malnutrition. But, if leprosy is a lesser problem, that is all the more reason why a strong effort should be made to solve it rapidly. Also an attack on leprosy' along the lines indicated above will tend to clear the way for dealing with such conditions as tuberculosis and malnutriticn, which, though more serious and widespread, are less feared by the public.

I wish to express m' ${ }^{\prime}$ gratitude to $\mathrm{His}$ Excellency the Governor for the interest he has taken in the objects of my visit, and to the Chief Medical Officer who planned my programme and spared no effort towards making it a success. 